\title{
Cytotoxic Evaluation of the Essential Oils from Korean Native Plant on Human Skin and Lung Cells ${ }^{1}$
}

\author{
Changhwan $\mathrm{AHN}^{2,3} \cdot$ Yeong-Min $\mathrm{YOO}^{3} \cdot \mathrm{Mi}-\mathrm{Jin} \mathrm{PARK}^{4} \cdot$ \\ Youngseok $\mathrm{HAM}^{4} \cdot$ Jiyoon $\mathrm{YANG}^{4} \cdot$ Eui-Bae JEUNG ${ }^{3, \uparrow}$
}

\begin{abstract}
Plant essential oils are used in products such as fragrances and cosmetics due to their individual aromatic characteristics. Currently, essential oils are not only used in cosmetics but also in pharmaceutical products with anti-bacterial, anti-viral, anti-fungal, anti-parasitic, insecticidal, anti-cancer, neuroprotective, psychophysiological, or anti-aging effects. Despite their pharmaceutical properties, some studies reported cytotoxic effects in high doses. Therefore, for pharmaceutical purposes, the margin of safety of essential oils needs to be examined. Herein, we evaluated the $\mathrm{IC}_{50}$ of 10 essential oil from Korean native plants: Juniperus chinensis L. var. sargentii Henry, Citrus natsudaidai Hayata, Citrus reticulata Blanco, Citrus unshiu (Yu. Tanaka ex Swingle) Marcow, Artemisia capillaris Thunb, Aster glehnii F. Schmidt, Juniperus chinensis L, Zanthoxylum schinifolium Siebold \& Zucc, Zanthoxylum piperitum (L.) D, and Cinnamomum loureirii. In addition, gene regulation of the cell-cycle gene and apoptosis marker CASP3 was examined at the $\mathrm{IC}_{50}$ level. The purpose of this study was to describe the toxic concentrations of essential oils extracted from Korean native plants, thereby providing toxic concentration guidelines for inclusion in a toxicity database and in the application of plant essential oils in various fields.
\end{abstract}

Keywords: essential oil, cytostatic effect, cell death, skin, lung

\section{INTRODUCTION}

Essential oils are secondary plant metabolites mainly composed of monoterpenes and sesquiterpenes (Mahmoud et al., 2002; Min et al., 2017). Essential oils have been of interest worldwide for their application in alternative medicines to treat diseases and for their stress-relieving, anti-inflammatory, anti-oxidant, and anti-microbial properties (Pujiarti et al., 2016; Elshafie et al., 2017; Yang et al., 2019; Ham et al., 2020; Lee et al., 2021). Whereas, at the same time, researchers have indicated that essential oils need further research (Farrar et al., 2020). Systematic and rigorous approaches to studying the biological activities

\footnotetext{
${ }^{1}$ Date Received May 18, 2021, Date Accepted July 12, 2021

2 Laboratory of Veterinary Physiology, College of Veterinary Medicine, Jeju National University, Jeju, 63243, Republic of Korea

${ }^{3}$ Laboratory of Veterinary Biochemistry and Molecular Biology, College of Veterinary Medicine, Chungbuk National University, Cheongju, Chungbuk 28644, Republic of Korea

${ }^{4}$ Division of Forest industrial Materials, Department of Forest Products and Industry, National Institute of Forest Science, Seoul 02455, Republic of Korea

$\dagger$ Corresponding author: Eui-Bae JEUNG (e-mail: ebjeung@chungbuk.ac.kr, ORCID: 0000-0001-8936-916X)
} 
of potential phytotherapeutics have only been initiated in recent decades (Ahn et al., 2018; Ahn et al., 2020). Phytotherapeutics such as essential oils are natural substances, but natural should not be considered synonymous with harmless. Evaluation of the toxicity of essential oils and regulation of their use are underway. The toxicity of essential oil may be considered trivial compared to that of conventional medicines; however, such essential oils could bring forth severe public health problems as the occurrence of side effects of essential oils is common. Moreover, there is possible toxicity resulting from improper use. Toxicity tests are designed to assess or predict toxic effects in vivo and to assess the relative toxicity of substances. In vitro cytotoxicity assaying is the first approach to evaluating the biocompatibility of an essential oil (Rogero et al., 2003).

Natural products such as essential oils can also interact with DNA, producing changes in its structure or function, and such modifications can trigger the cell replication system (Edris, 2007). A cell replication cycle is a series of events within a cell as it grows and divides. A cell spends most of its time in what is called interphase, and during this time, it grows, replicates its chromosomes, and prepares for cell division (Baserga, 1965). The G1/S and G2/M cell-cycle checkpoints maintain genomic stability in eukaryotes in response to genotoxic stress (Wang et al., 1999).

Cinnamomum loureirii is from the plant family Lauraceae, which has a worldwide distribution in tropical and warm climates. Many Lauraceae contain high concentrations of essential oils, some of which are valued for use in spices and perfumes (Prabuseenivasan et al., 2006). Within Lauraceae plants, most such substances are components of their irritant or toxic saps or tissues, which may repel or poison many herbivorous or parasitic organisms (Schausberger, 2018). Juniperus chinensis L. and Juniperus chinensis L. var. sargentii Henry is from the plant family Cupressaceae. The Cupressaceae may be a rich source of anti-tick com- pounds, and further investigation of cypress species for repellent and insecticidal chemicals is warranted (Dolan et al., 2007; Dolan et al., 2009). Aster glehnii F. Schmidt and Artemisia capillaris Thunb. are from the plant family Asteraceae, which includes more than 1,600 genera and 20,000 species of herbs and trees worldwide. Zanthoxylum schinifolium Siebold \& Zucc, Zanthoxylum piperitum (L.) DC, Citrus natsudaidai Hayata, Citrus unshiu (Yu. Tanaka ex Swingle) Marcow, and Citrus reticulata Blanco are members of the Rutaceae plant family. Rutaceae members are considered good sources of essential oil. Some family members are Amyris (Amyris balsamifera), Bergamot (Citrus bergamia), Boronia (Boronia megastigma), Cape May (Coleonema album), Clementine (Citrus clementina), Grapefruit (Citrus paradisi), Lemon (Citrus limonum), Lime (Citrus aurantifolia), Mandarin (Citrus reticulata), Neroli (Citrus aurantium var.amara), Orange Blood (Citrus sinensis), Orange Sweet (Citrus sinensis), Petitgrain (Citrus aurantium var. amara), Rue (Ruta graveolens), Tangerine (Citrus reticulata), Tosa Konatsu (Citrus tamurana), Xanthoxylum (Zanthoxylum armatum), Yuzu (Citrus junos), and Zanthoxylum (Zanthoxylum odorum), each of which is a source of essential oils.

This study was undertaken to examine the cytotoxic dosage of essential oils of several Korean native plants, with that dosage based on the $\mathrm{IC}_{50}$ values obtained in human lung (A549) and human skin (Detroit551) cells of oils extracted from Cinnamomum loureirii, Juniperus chinensis L., Aster glehnii F. Schmidt, Artemisia capillaris Thunb, Juniperus chinensis L., Juniperus chinensis L. var. sargentii Henry, Citrus natsudaidai Hayata, Citrus unshiu (Yu. Tanaka ex Swingle) Marcow, and Citrus reticulata Blanco. In addition, the cytotoxic mechanisms of the examined essential oils were determined by examining changes in the gene and protein expressions of four cell-cycle markers (Cyclin A, Cyclin B, Cyclin D, and Cyclin E) and one cell-death marker (caspase-3). 


\section{MATERIALS and METHODS}

\subsection{Extraction of plant essential oils}

Plant essential oils are extracted by hydrodistillation with $1 \mathrm{~kg}$ of plant leafs and $10 \mathrm{~L}$ of distilled water on heating mantle (Catalog number: MS-DM608, MTOPS $^{\circledR}$, Seoul, Republic of Korea) at $102^{\circ} \mathrm{C}$. Volatile steam are condensed in dean stark trap. Acquired essential oils are dehydration with sodium sulfite anhydrous, and then stored at $4{ }^{\circ} \mathrm{C}$.

\subsection{Cell Count Kit assay}

A549 (KCLB No: 10185) and Detroit 551 cells (KCLB No: 10110) from Korean cell line bank (Seoul, Republic of Korea) were seeded at a density of 0.5 $\times 10^{3}$ cells per well in 6 -well plate and the medium used for cell culture was DMEM high glucose media (Catalog number: L0102, Biowest, Nuaillé, France) supplemented with penicillin-streptomycin solution (Catalog number: L0018 Biowest), Plasmocin ${ }^{\mathrm{TM}}$ prophylactic (Catalog number: ant-mpp, InvivoGen, San Diego, USA) and fetal bovine serum (Catalog number: 16140071, Thermo Fisher Scientific Korea Ltd., Seoul, Republic of Korea). Cells were incubated in a $\mathrm{CO}_{2}$ atmosphere at $37^{\circ} \mathrm{C}$ for $24 \mathrm{~h}$ prior to treating with essential oil. The plant essential oils were prepared in four concentrations of $10^{-8}, 10^{-6}, 10^{-4}$, and $10^{-2}$. After $24 \mathrm{~h}$ incubation, the cells are treated with diluted plant essential oil and incubated for $24 \mathrm{~h}$ additionally. Subsequently, the plant essential oil and the medium treating the cells were removed and the cells washed with PBS solution (Catalog number: LB 001-02, WELGENE Inc., Gyeongsan, Republic of Korea). EZ-Cytox enhanced cell viability assay reagent (Catalog number: EZ-1000, DoGenBio Co., Ltd., Seoul, Republic of Korea) at the recommended concentration was then placed in each well. One hour later, the absorbance value at $450 \mathrm{~nm}$ was measured with an
Epoch microplate spectrophotometer (Catalog number: Epoch, BioTek Instruments, Inc., Vermont, USA). Cell viability (\%) was determine by using the formula of optical density (OD) of sample treated cells / OD of untreated cells as the control $\times 100$ for each tested concentration. A cell survival curve was calculated from those values, and the $\mathrm{IC}_{50}$ value was determined. After conducting the CCK assay, the same procedure was repeated with plant essential oils that were diluted to concentrations of $10^{-6}, 10^{-5}, 10^{-4}, 10^{-3}$, and $10^{-2}$.

\subsection{Reverse-transcription real-time polymerase chain reaction}

Cells were seeded in 6-well plates at a density of $0.3 \times 10^{-4}$ cells per well and incubated at $37^{\circ} \mathrm{C}$ in $5 \%$ $\mathrm{CO}_{2}$ atmosphere. Plant essential oils in DMEM high glucose media were prepared in three concentrations: $\mathrm{IC}_{50}$ from the $\mathrm{CCK}$ assay, 10 times more than the $\mathrm{IC}_{50}$, and 10 times less than the $\mathrm{IC}_{50}$. When cell confluency was $70 \%$, the cells were treated with the appropriate concentration of plant essential oil. Harvesting of cells and RNA extraction were accomplished by using TRI Reagent $^{\mathrm{TM}}$ Solution (Catalog number: AM9738, Thermo Fisher Scientific Korea Ltd.) at $24 \mathrm{~h}$ after plant essential oil treatment. The purity and concentration of the extracted RNA were measured by using an Epoch microplate spectrophotometer.

The extracted RNA was synthesized by reverse transcription. The concentration of RNA was titrated to $1 \mu \mathrm{g} / \mu \mathrm{L}$ and DEPC-treated water was added to adjust the total volume to $10.5 \mu \mathrm{L}$. The mixture contained Moloney murine leukemia virus (MMLV) reverse transcriptase (Catalog number: 28025013, Invitrogen, Massachusetts, USA), Ribonuclease inhibitor (Invitrogen), random primers (Catalog number: 3801, TaKaRa, Kyoto, Japan), $100 \mathrm{mM}$ DTT (Invitrogen), dNTP and 5× first strand buffer (Catalog number: 28025013, Invitrogen). The reaction mixture was incubated at $37^{\circ} \mathrm{C}$ for 60 min. After incubation, the cells were incubated further 
at $95^{\circ} \mathrm{C}$ for $5 \mathrm{~min}$ for inactivation of the enzyme. After cooling for $5 \mathrm{~min}$ on ice, the cDNA was stored at $-20^{\circ} \mathrm{C}$ prior to use.

For real-time polymerase chain reaction (RT-PCR), a mastermix of the following reaction components was prepared: cDNA sample $(2 \mu \mathrm{L}), 0.25 \mu \mathrm{L} 50 \times \operatorname{ROX}$ dye, $6.25 \mu \mathrm{L} 2 \times$ prime Q-mastermix SYBR (Catalog number: Q-9210, GeNetBio, Daejeon, Republic of Korea), $0.5 \mu \mathrm{L}$ forward primer, and $0.5 \mu \mathrm{L}$ reverse primer. RT-PCR was performed using 7300 RT-PCR system (Applied Biosystems, Foster City, CA, USA) and the procedure sequence was as follows: cDNA denatured at $95^{\circ} \mathrm{C}$ for $30 \mathrm{sec}$ and annealed at $58^{\circ} \mathrm{C}$ for $30 \mathrm{sec}$, elongation is performed at $72^{\circ} \mathrm{C}$ for $30 \mathrm{sec}$, and the whole cycle is repeated 40 times. The degree of gene expression was determined by using RQ software (Applied Biosystems).

The primer sequences used are as follows: 5'-CATACTCCACAGCACCTGGTTA-3' (forward) and 5'-CTGTTGCCACCTTTCGGTTA-3' (reverse) for CASP3; 5'-TACTTTCTGCATCAGCAGCC-3' (forward) and 5'-TGATTCAGGCCAGCTTTGTC-3' (reverse) for Cyclin A; 5'-CTTTGCACTTCCTTCGGAGA-3' (forward) and GTAGAGTTGGTGTCCATTCACC-3' (reverse) for Cyclin B; 5'-CCTCGGTGTCCTACTTCA-3' (forward) and 5'-CTCCTCGCACTTCTGTTC-3' (reverse) for Cyclin D; and 5'-GGTTTCAGGGRATCAGTGGT-3' (forward) and 5'-TTTCTTTGCTCGGGGCTTTG-3' (reverse) for Cyclin E. The primer sequence for Rn18s was used as the primer for the control group: 5'-CTCAACACGGGAAACCTCAC-3' (forward) and 5'-CGCTCCACCAACTAAGAACG-3' (reverse). All primers were obtained from Macrogen (Korea).

\subsection{Western blotting}

Proteins were extracted using Pro-prep (iNtRON Biotechnology, Seongnam, Republic of Korea) according to the manufacturer's instructions. Proteins (30 $\mu \mathrm{g}$ per lane) were separated on a $10 \%$ SDS-PAGE gel and transferred to a polyvinylidene fluoride transfer membrane (catalog number: NEF1000, PerkinElmer Inc., Seoul, Republic of Korea) in a TransBlot Cell (catalog number: TE-22; Hoefer Co. Massachusetts, USA) according to the manufacturer's instructions. The resulting blot was blocked with TBS-T containing 5\% skimmed milk for $60 \mathrm{~min}$, then incubated with primary antibody: Caspase-3 (mouse monoclonal, 1:500, Catalog number: 9665, Cell Signaling Technology, Massachusetts, USA), Cyclin A2 (mouse monoclonal, 1:500, Catalog number: 4656, Cell Signaling Technology), Cyclin B1 (rabbit polyclonal, 1:500, Catalog number: 4138, Cell Signaling Technology), Cyclin D1 (rabbit monoclonal, 1:500, Catalog number: 2978, Cell Signaling Technology), Cyclin E1 (mouse monoclonal, 1:500, Catalog number: 4129, Cell Signaling Technology), or $\beta$-actin (rabbit monoclonal, 1:1,000, Catalog number: 4970, Cell Signaling Technology). After washing in buffer, the membranes were incubated with the appropriate horseradish peroxidase-conjugated secondary antibodies (anti-goat, 1:2,000, Catalog number: sc-2354 or anti-mouse, 1:4,000, Catalog number: sc-2005, Santa Cruz, Texas, USA) for $1 \mathrm{~h}$ at room temperature. Next, the blots were developed by incubation in ECL chemiluminescence reagent (Catalog number: sc-2048, Santa Cruz) and subsequently exposed to the GeneGnome Bioimaging System (Catalog number: 77534-3, Syngene, Maryland, USA) for development, after which images were captured by using the GENESys software (Syngene). Signal specificity was confirmed by blotting in the absence of primary antibody, and bands were normalized to $\beta$-actin immunoreactive bands visualized on the same membrane after stripping. The density of each band was measured using the NIH ImageJ software.

\subsection{Data analysis}

All data were analyzed by applying nonparametric one-way analysis of variance followed by Tukey's test 
for multiple comparisons. All experiments consisted of three separate trials. Statistical analysis was performed by using Prism Graph Pad (v.8.0; GraphPad Software, San Diego, USA).

\section{RESULTS and DISCUSSION}

\subsection{Examination of $\mathrm{IC}_{50}$ value of each essential oils}

The CCK assay was used to obtain $\mathrm{IC}_{50}$ values of each essential oil. To determine that concentration, cells were treated with four concentrations of each essential oil, followed by a further subdivision of the doses using the $\mathrm{CCK}$ assay. The $\mathrm{IC}_{50}$ values for the ten plant essential oils tested are presented in Fig. 1 and 2. In the Detroit-551 and A549 cell lines, the degree of cytotoxicity of each essential oil was compared with its $\mathrm{IC}_{50}$ value. The essential oil $\mathrm{IC}_{50}$ values obtained from
Detroit-551 cell assays were Artemisia capillaris Thunb. $\left(5.4510^{-3}\right)$, Aster glehnii F. Schmidt $\left(2.9410^{-3}\right)$, Zanthoxylum piperitum (L.) DC $\left(1.6410^{-2}\right)$, Zanthoxylum schinifolium Siebold \& Zucc. $\left(1.5610^{-2}\right)$, Juniperus chinensis L. $\left(4.5310^{-3}\right)$, Juniperus chinensis L. var. sargentii Henry $\left(5.5910^{-3}\right)$, Cinnamomum loureirii Nees $\left(1.0910^{-4}\right)$, Citrus reticulata Blanco $\left(2.7710^{-3}\right)$, Citrus natsudaidai Hayata $\left(5.8010^{-3}\right)$, and Citrus unshiu (Yu. Tanaka ex Swingle) Marcow $\left(3.1610^{-3}\right)$. Similarly, the essential oil $\mathrm{IC}_{50}$ values obtained from A549 cell assays were Artemisia capillaris Thunb. $\left(1.9110^{-3}\right)$, Aster glehnii F. Schmidt $\left(2.7710^{-3}\right)$, Zanthoxylum piperitum (L.) DC $\left(1.5910^{-2}\right)$, Zanthoxylum schinifolium Siebold \& Zucc. $\left(1.3010^{-2}\right)$, Juniperus chinensis L. $\left(2.7910^{-3}\right)$, Juniperus chinensis L. var. sargentii Henry $\left(4.1510^{-3}\right)$, Cinnamomum loureirii Nees $\left(7.4610^{-4}\right)$, Citrus reticulata Blanco $\left(1.0210^{-3}\right)$, Citrus natsudaidai Hayata $\left(6.5910^{-3}\right)$, and Citrus unshiu (Yu. Tanaka ex Swingle) Marcow $\left(2.3410^{-3}\right)$.
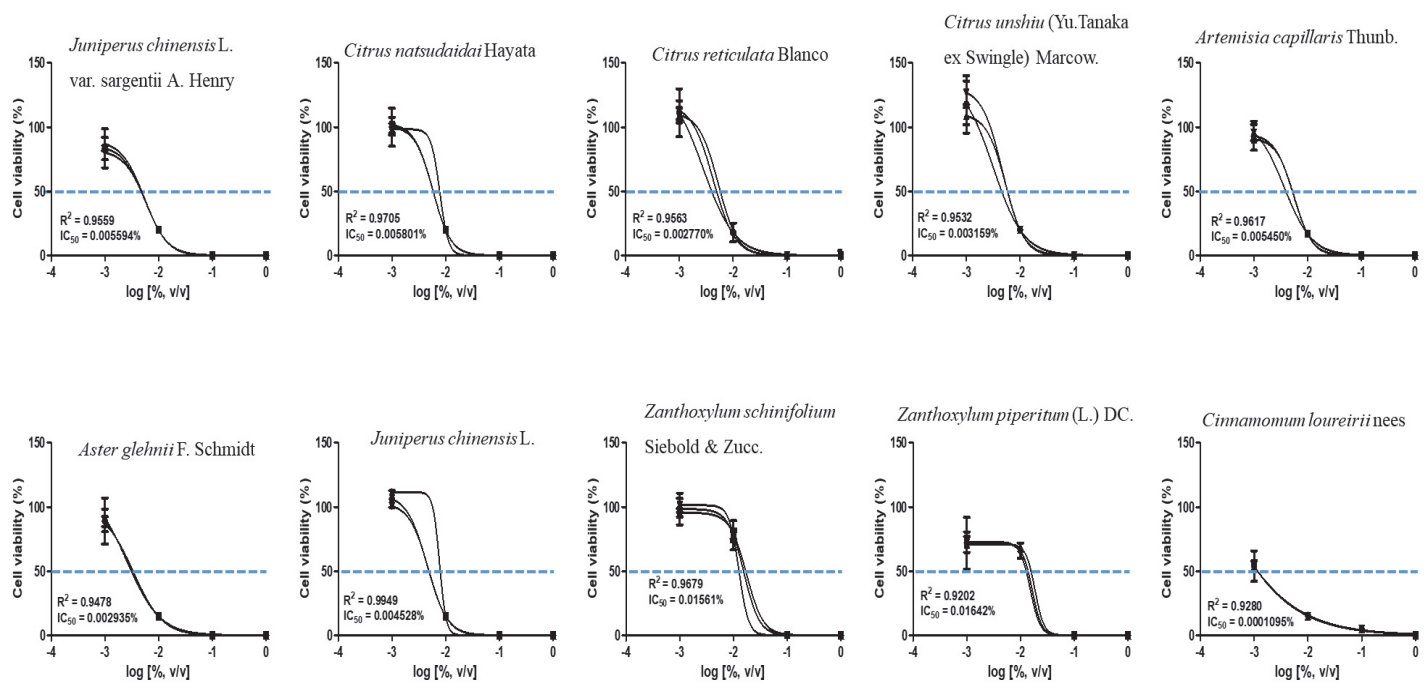

Fig. 1. Cell survival curves for determining the $\mathrm{IC}_{50}$ values of essential oil in the Detroit-551 cell line. Through the foregoing experiments conducted to determine the experimental concentration, the essential oil was diluted to a more detailed five concentrations; $10^{-4}, 10^{-3}, 10^{-2}, 10^{-1}$, and $10^{-0}(\%$, v/v). After the cells are treated with essential oils, the OD value was measured using the CCK assay. Cell viability was determined by OD value (treated) / OD value (untreated) $\times 100(\%)$, and the $\mathrm{IC}_{50}$ value is measured through the drawn survival curve 

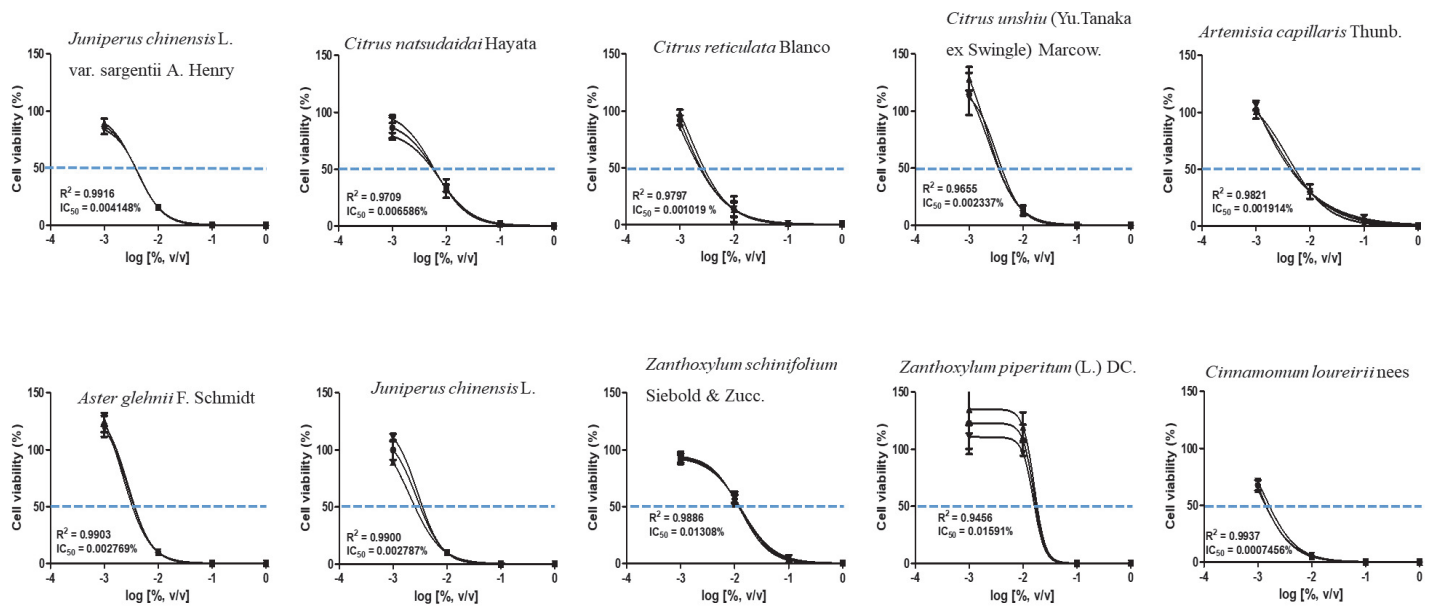

Fig. 2. Cell survival curves for determining the $\mathrm{IC}_{50}$ values of essential oil in the A549 cell line.

Through the foregoing experiments conducted to determine the experimental concentration, the essential oil was diluted to a more detailed five concentrations; $10^{-4}, 10^{-3}, 10^{-2}, 10^{-1}$, and $10^{-0}(\%$, v/v). After the cells are treated with essential oils, the OD value was measured using the CCK assay. Cell viability was determined by OD value (treated) / OD value (untreated) $\times 100(\%)$, and the $\mathrm{IC}_{50}$ value is measured through the drawn survival curve

(A)

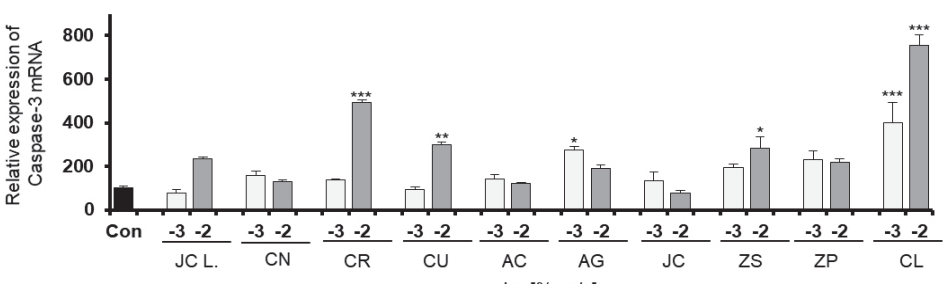

(B)

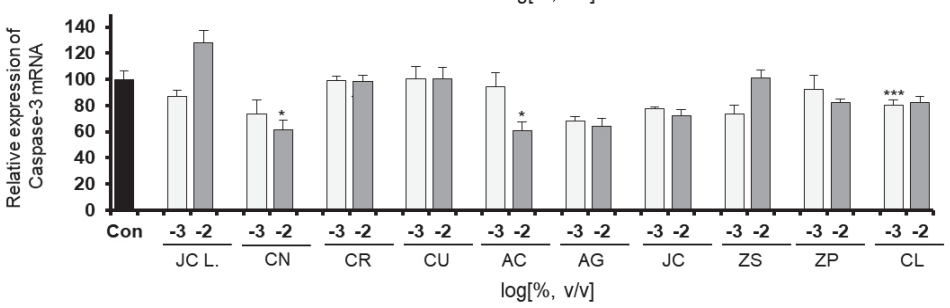

Fig. 3. The expression level of CASP3 in Detroit-551 and A549 cells after treatment with essential oil. Relative expression of CASP3 in Detroit-551 (A) and A549 cell line (B). Based on the $\mathrm{IC}_{50}$ values obtained above, two concentrations were set so that the difference was ten times near $\mathrm{IC}_{50}$. The expression levels of CASP3 in each group were determined by real-time polymerase chain reaction after 24 hours of essential oil treatment. (Juniperus chinensis L. var. sargentii Henry; JC L., Citrus natsudaidai Hayata; CN., Citrus reticulata Blanco; CR., Citrus unshiu (Yu.Tanaka ex Swingle) Marcow; CU., Artemisia capillaris Thunb; AC., Aster glehnii F. Schmidt; AG., Juniperus chinensis L; JC., Zanthoxylum schinifolium Siebold \& Zucc; ZS., Zanthoxylum piperitum (L.) DC; ZP., Cinnamomum loureirii Nees; CL.). 


\section{2. mRNA expression of CASP3 gene with plant essential oils}

The expression levels of CASP3, a marker gene related to cellular apoptosis, were determined by performing quantitative RT-PCR of cells after essential oil treatment. The expression levels of CASP3 in the A549 and Detroit-551 cells after treatment with each of the ten plant essential oils are shown in Fig. 3. The expression of CASP3 in Detroit-551 cells increased at concentrations near the $\mathrm{IC}_{50}$ values of Citrus reticulata Blanco, Citrus unshiu (Yu. Tanaka ex Swingle) Marcow, Aster glehnii F. Schmidt, Zanthoxylum schinifolium
Siebold \& Zucc, Cinnamomum loureirii Nees. However, none of the ten essential oils increased CASP3 mRNA expression in A549 cells.

\section{3. mRNA expression of Cyclin A, Cyclin B, Cyclin D, and Cyclin E with plant essential oils}

The expression levels of Cyclin A, Cyclin B, Cyclin D, and Cyclin E when Detroit-551 cells were treated with $10^{-2}$ and $10^{-3} \%(\mathrm{v} / \mathrm{v})$ concentrations of the ten essential oils are shown in Fig. 4. The cell-cycle control gene, Cyclin A, showed an increased expression

(A)

(B)
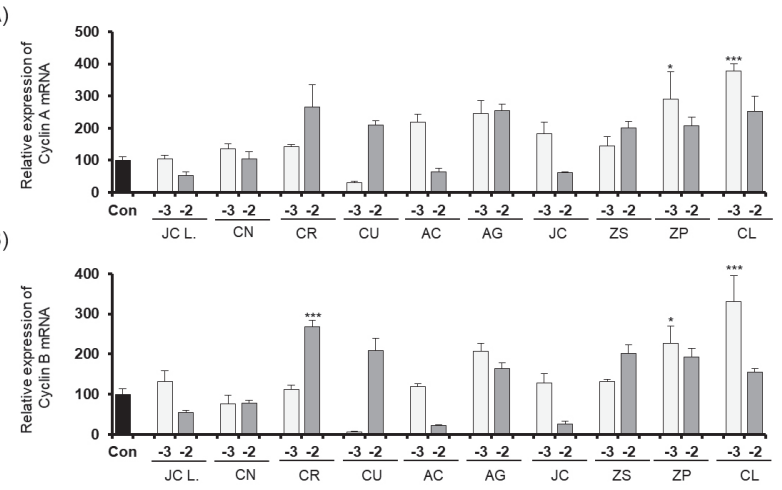

(C)

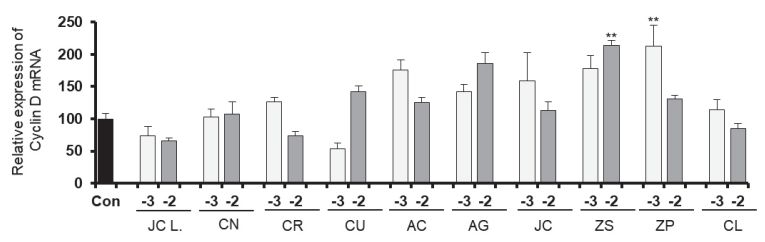

(D)

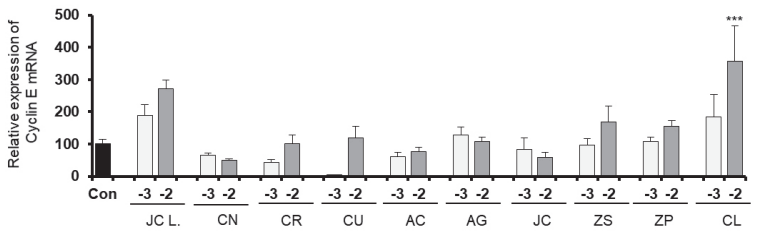

Fig. 4. The expression level of CycllinA, Cyclin B, Cyclin D, and Cyclin E in Detroit-551 cells after treatment with essential oil.

Based on the $\mathrm{IC}_{50}$ values obtained above, two concentrations were set so that the difference was ten times. The expression levels Cyclin A (A), Cyclin B (B), Cyclin D (C), and Cyclin E (D) in the Detroit-551 cell line were determined by real-time polymerase chain reaction after 24 hours of essential oil treatment. The abbreviations of plant names were shown in the legend of Fig. 3 . 
(A)

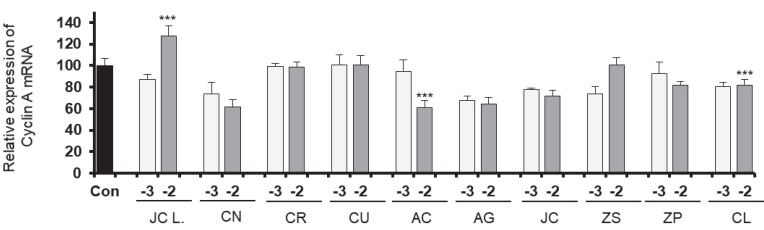

(B)

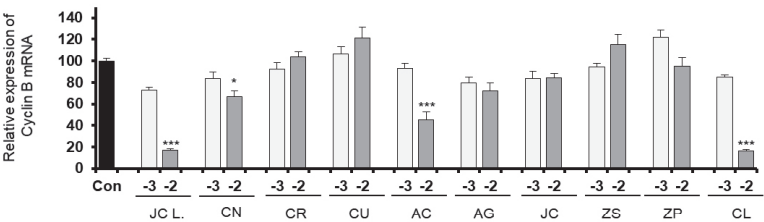

(C)

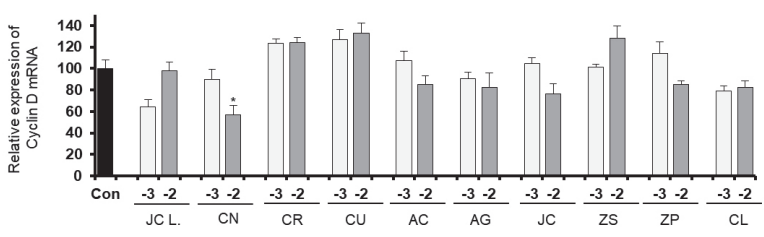

(D)

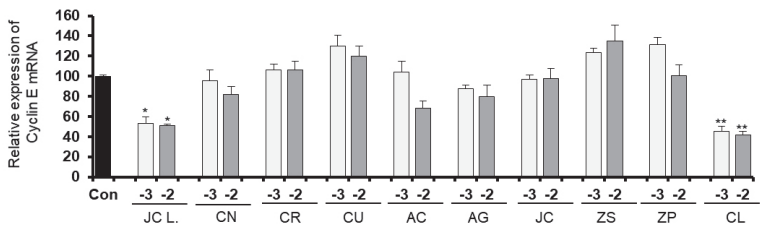

Fig. 5. The expression level of CycllinA, Cyclin B, Cyclin D, and Cyclin E in A549 cells after treatment with essential oil.

Based on the $\mathrm{IC}_{50}$ values obtained above, two concentrations were set so that the difference was ten times. The expression levels Cyclin A (A), Cyclin B (B), Cyclin D (C), and Cyclin E (D) in the A549 cell line were determined by real-time polymerase chain reaction after 24 hours of essential oil treatment. The abbreviations of plant names were shown in the legend of Fig. 3.

following Cinnamomum loureirii Nees treatment. Cyclin B showed increased expression levels following treatment with essential oils of Citrus reticulata Blanco, Zanthoxylum piperitum (L.) DC, Cinnamomum loureirii Nees. Zanthoxylum schinifolium Siebold \& Zucc., and Zanthoxylum piperitum (L.) Only the Zanthoxylum piperitum (L.) DC treatment produced an increased level of Cyclin D expression, and Cinnamomum loureirii Nees was the only essential oil that induced an increase in Cyclin E expression.

In the A549 cell line, only Juniperus chinensis L. var. sargentii Henry treatment $\left(10^{-2} \% \mathrm{v} / \mathrm{v}\right.$ concen- tration) induced an increase in Cyclin A expression. None of the ten essential oil treatments increased the expressions of cyclins B, D, and E in A549 cells.

\subsection{Protein expression of cell apoptosis marker caspase-3 and cell-cycle marker genes with plant essential oil treatment}

At the protein level, expressions of cyclins A and Cyclin B were increased in Detroit-551 cells, results considered to indicate the cells were in mitosis or the $\mathrm{S}$ phase of the cell cycle. Cyclin B was increased fol- 

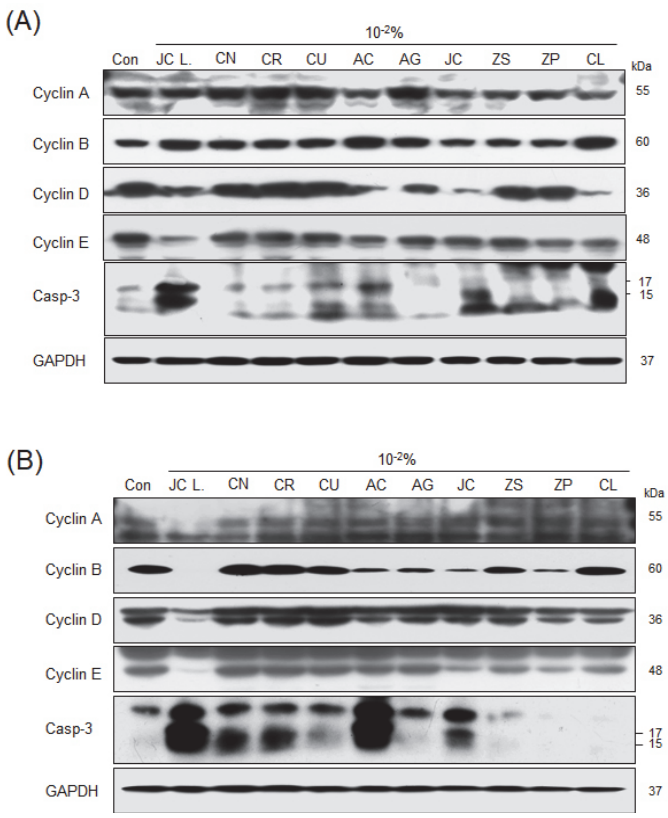

Fig. 6. The expression level of Cyclin A, Cyclin B, Cyclin D, and Cyclin E in Detroit-551 cells after treatment with essential oil.

Based on the $\mathrm{IC}_{50}$ values obtained above, the higher dose of essential oil $10^{-2}(\%, \mathrm{v} / \mathrm{v})$ was chosen to examine protein expression of cell cycle markers and cell apoptosis marker gene. The expression levels Cyclin A, Cyclin B, Cyclin D, Cyclin E, and Caspase-3 in each group were determined by western blotting after 24 hrs of essential oil treatment. The abbreviations of plant names were shown in the legend of Fig. 3.

lowing Citrus unshiu (Yu. Tanaka ex Swingle) Marcow, Artemisia capillaris Thunb, Aster glehnii F. Schmidt, and Cinnamomum loureirii Nees treatments. Notably, caspase-3 expression was increased in Detroit-551 cells treated with Juniperus chinensis L. var. sargentii Henry, Citrus unshiu (Yu. Tanaka ex Swingle) Marcow, Artemisia capillaris Thunb, Juniperus chinensis L, and Cinnamomum loureirii Nees. In the treated A549 cells, Cyclin A expression was increased with Citrus reticulata Blanco, Citrus unshiu (Yu. Tanaka ex Swingle) Marcow, Zanthoxylum schinifolium Siebold \& Zucc, Zanthoxylum piperitum (L.) DC, and Cinnamomum loureirii Nees treatments. In addition, caspase-3 expression increased with Juniperus chinensis L. var. sargentii Henry, Citrus natsudaidai Hayata, Citrus reticulata Blanco, Citrus unshiu (Yu.
Tanaka ex Swingle) Marcow, Artemisia capillaris Thunb, and Juniperus chinensis L. treatments.

\subsection{Discussion}

Essential oils have been used in traditional medicines, and systematic, scientific examination of the biological activities of essential oil from plants has been conducted for several decades (Borges et al., 2005; Mohammadhosseini et al., 2017). Traditional herbal medicines, including essential oils, have been used for treating infections and modulating various physiological functions (Horvath et al., 2015). Essential oils also have great potential as anti-inflammatory, anti-bacterial, and anti-cancer therapeutic agents (Bravo et al., 1980; Pagano et al., 1992; Elledge, 1996). However, dosages and the methods for oil extraction 
are inconsistent, which can result in cytotoxic effects when using essential oils. In addition, reports describing the mechanisms of essential oil cytotoxicity are lacking. Indeed, the complex chemical composition of plant essential oil extracts makes it difficult to evaluate a mechanism of action underlying the biological effects such as cell toxicity, cytostatic effects, and side effects (Ahn et al., 2020).

The cytotoxic mechanisms associated with plant essential oils are typically divided into two types: apoptosis and necrosis; both of which are cytotoxic mechanisms that can kill cells or inhibit cell growth by delaying the cell cycle and inhibiting cell proliferation.

The cell cycle is divided into the $\mathrm{S}$ phase, the time when DNA is doubled, the $M$ phase, when chromosome distribution and cell division occurs, and the G1 and G2 phases, which occur between these $\mathrm{S}$ and $\mathrm{M}$ phases; the overall cycle is a periodic sequence of phases G1, S, G2, and M (Gerdes et al., 1984). Each phase of the cell cycle and its progression to the next phase are regulated by a complex of cyclins and cyclin-dependent kinases (CDK) (Peter et al., 1994). In the G1 phase, Cyclin D/CDK4/6 and Cyclin E/CDK2 act in sequence (Peter et al., 1994). Cell-cycle regulation maintains genome stability by checking for genome damage and ensuring the cellular DNA is re- plicated during one cell cycle before division into two daughter cells (Bartek et al., 2004). If the cell cycle and checkpoint system are not functioning normally, cells may die or cause chromosome instability, resulting in fatal diseases such as cancer (Gerlach et al., 2020). Cells that do not undergo cell division exhibit apoptosis or programmed cell death. When cell death occurs, a signal is transmitted to neighboring cells (Kawamoto et al., 2016). Malfunctioning cells that undergo apoptosis or death are beneficial to the survival of an organism. In addition, recent reports have defined many roles for apoptosis in normal lung function and in pathophysiology unrelated to lung neoplasia (Schittny et al., 1998). Detroit-551 cells are representative of epithelial cells, such as skin cells, whereas A549 cells are adenocarcinomic human alveolar basal epithelial cells, have been used in type II cell study, and are sensitive to lung damage. Using these two cell types, we examined the cytostatic and cytotoxic effects of essential oils of ten Korean native plants.

In this study, by determining $\mathrm{IC}_{50}$ values and the expression levels of cellular apoptosis marker caspase- 3 and cell-cycle markers cyclins A, B, D, and $\mathrm{E}$, we examined the cell number reduction effects in ten essential oils at concentrations near the $\mathrm{IC}_{50}$ concentration. The apoptosis marker CASP3 displays

Table 1. Physical properties of the essential oil from Korean native plants

\begin{tabular}{ccccc}
\hline Species & Yield & Acidity & Density (g/ml) & Refraction \\
\hline \hline Juniperus chinensis L. var. sargentii Henry & $3.92 \pm 0.13$ & $0.94 \pm 0.02$ & 0.87 & 1.48 \\
Citrus natsudaidai Hayata & $5.88 \pm 0.23$ & $0.87 \pm 0.04$ & 0.84 & 1.47 \\
Citrus reticulata Blanco & 5.35 & $3.34 \pm 0.16$ & 0.84 & 1.47 \\
Citrus unshiu (Yu.Tanaka ex Swingle) Marcow. & $5.26 \pm 0.13$ & $1.12 \pm 0.08$ & 0.83 & 1.47 \\
Artemisia capillaris Thunb. & $0.30 \pm 0.05$ & $4.33 \pm 0.18$ & 0.88 & 1.51 \\
Aster glehnii F. Schmidt & $0.31 \pm 0.20$ & $2.48 \pm 0.10$ & 0.83 & 1.48 \\
Juniperus chinensis L. & $1.69 \pm 0.35$ & $1.26 \pm 0.00$ & 0.88 & 1.47 \\
Zanthoxylum schinifolium Siebold \& Zucc. & $2.34 \pm 0.81$ & $0.94 \pm 0.02$ & 0.93 & 1.52 \\
Zanthoxylum piperitum (L.) DC. & $2.97 \pm 0.70$ & $0.98 \pm 0.12$ & 0.83 & 1.47 \\
Cinnamomum loureirii Nees & $0.58 \pm 0.18$ & $3.10 \pm 0.22$ & 0.88 & 1.48 \\
\hline
\end{tabular}


an increase in gene expression upon apoptosis; thus, we evaluated cytotoxic effects based on protein expression levels. At the protein level, caspase-3 expressions were increased due to Juniperus chinensis L. var. sargentii Henry, Citrus unshiu Marcow, Artemisia capillaris Thunb, Juniperus chinensis L, Cinnamomum loureirii Nees in Detroit-551. Otherwise, caspase-3 expressions were increased by Juniperus chinensis L. var. sargentii Henry, Citrus natsudaidai Hayata, Citrus reticulata Blanco, Citrus unshiu Marcow, Artemisia capillaris Thunb, Juniperus chinensis L. Those results indicates that the decrease of the cell proliferation near $\mathrm{IC}_{50}$ value was from increased level of caspase- 3 induced cell death by those essential oils treatment.

A relatively high dose of essential oil $\left(10^{-2}\right)$ induced Cyclin A increases in Detroit-551 cells, which is indicative of mitosis or the $\mathrm{S}$ phase arrest in the cell cycle. M phase arrest may induced by Citrus unshiu (Yu. Tanaka ex Swingle) Marcow, Artemisia capillaris Thunb, Aster glehnii F. Schmidt, and Cinnamomum loureirii Nees treatment in order to increased Cyclin B. Similarly, in A549 cells, Cyclin A was increased with Citrus reticulata Blanco, Citrus unshiu (Yu. Tanaka ex Swingle) Marcow, Zanthoxylum schinifolium Siebold \& Zucc, Zanthoxylum piperitum (L.) DC, and Cinnamomum loureirii Nees treatments.

In shorts, essential oil from Juniperus chinensis L. var. sargentii Henry, Juniperus chinensis L. induce cell death by apoptosis in order to increase expression of caspase-3. Citrus unshiu, Artemisia capillaris Thunb essential oils induce cell death by cytostatic effects in order to cell cycle arrest and inducing apoptosis. Citrus natsudaidai Hayata, Citrus reticulata Blanco, Cinnamomum loureirii Nees essential oils can induce both cytostatic and apoptotic effect depends on cell type. Other essential oil from Aster glehnii F. Schmidt, Zanthoxylum schinifolium Siebold \& Zucc., Zanthoxylum piperitum (L.) DC induce only cytostatic effect in order to cell cycle arrest. This result is need to be considered before development and application of these essential oils.

\section{CONCLUSION}

Based on the results, essential oils from various plants can produce cytotoxic and cytostatic effects. Such effects should be evaluated further to predict potential side effects of the clinical usage of essential oils. The pharmacological properties of essential oils depend on their chemical contents and the concentrations used. Careful selection of a treatment concentration is important when using plant essential oils for medicinal or cosmetic purposes.

\section{ACKNOWLEDGMENT}

This work was supported by the Forest Science Technology Program (Project No. 1405004579) provided by National Institute of Forest Science and the Global Research and Development Center (GRDC) Program through the National Research Foundation of Korea (NRF) funded by the Ministry of Education, Science and Technology (2017K1A4A3014959).

\section{REFERENCES}

Ahn, C., Lee, J.H., Park, M.J., Kim, J.W., Yang, J., Yoo, Y.M., Jeung, E.B. 2020. Cytostatic effects of plant essential oils on human skin and lung cells. Experimental and Therapeutic Medicine 19(3): 2008-2018.

Ahn, C., Park, M.J., Kim, J.W., Yang, J., Lee, S.S., Jeung, E.B. 2018. Cytotoxic evaluation of plant essential oils in human skin and lung cells. Journal of the Korean Wood Science and Technology 46(2): 166-177.

Bartek, J., Lukas, C., Lukas, J. 2004. Checking on DNA damage in S phase. Nature Reviews Molecular Cell 
Biology 5(10): 792-804.

Baserga, R. 1965. The relationship of the cell cycle to tumor growth and control of cell division: A review. Cancer Research 25: 581-595.

Borges, F., Roleira, F., Milhazes, N., Santana, L., Uriarte, E. 2005. Simple coumarins and analogues in medicinal chemistry: Occurrence, synthesis and biological activity. Current Medicinal Chemistry 12(8): 887-916.

Bravo, R., Celis, J.E. 1980. A search for differential polypeptide synthesis throughout the cell cycle of HeLa cells. Journal of Cell Biology 84(3): 795-802. Dolan, M.C., Dietrich, G., Panella, N.A., Montenieri, J.A., Karchesy, J.J. 2007. Biocidal activity of three wood essential oils against Ixodes scapularis (Acari: Ixodidae), Xenopsylla cheopis (Siphonaptera: Pulicidae), and Aedes aegypti (Diptera: Culicidae). Journal of Economic Entomology 100(2): 622-625.

Dolan, M.C., Jordan, R.A., Schulze, T.L., Schulze, C.J., Manning, M.C., Ruffolo, D., Schmidt, J.P., Piesman, J., Karchesy, J.J. 2009. Ability of two natural products, nootkatone and carvacrol, to suppress Ixodes scapularis and Amblyomma americanum (Acari: Ixodidae) in a Lyme disease endemic area of New Jersey. Journal of Economic Entomology 102(6): 2316-2324.

Edris, A.E. 2007. Pharmaceutical and therapeutic potentials of essential oils and their individual volatile constituents: A review. Phytotherapy Research 21(4): 308-323.

Elledge, S.J. 1996. Cell cycle checkpoints: Preventing an identity crisis. Science 274(5293): 1664-1672.

Elshafie, H.S., Camele, I. 2017. An Overview of the Biological Effects of Some Mediterranean Essential Oils on Human Health. BioMed Research International 2017: 9268468.

Farrar, A.J., Farrar, F.C. 2020. Clinical aromatherapy. Nursing Clinics of North America 55(4): 489-504. Gerdes, J., Lemke, H., Baisch, H., Wacker, H.H.,
Schwab, U., Stein, H. 1984. Cell cycle analysis of a cell proliferation-associated human nuclear antigen defined by the monoclonal antibody Ki-67. Journal of Immunology 133(4): 1710-1715.

Gerlach, S.U., Herranz, H. 2020. Genomic instability and cancer: Lessons from Drosophila. Open Biology 10(6): 200060.

Ham, Y., Yang, J., Choi, W.S., Ahn, B.J., Park, M.J. 2020. Antibacterial activity of essential oils from pinaceae leaves against fish pathogens. Journal of the Korean Wood Science and Technology 48(4): 527-547.

Horvath, G., Acs, K. 2015. Essential oils in the treatment of respiratory tract diseases highlighting their role in bacterial infections and their anti-inflammatory action: a review. Flavour and Fragrance Journal 30(5): 331-341.

Kawamoto, Y., Nakajima, Y.I., Kuranaga, E. 2016. Apoptosis in cellular society: Communication between apoptotic cells and their neighbors. International Journal of Molecular Sciences 17(12): $1-15$.

Lee, S.Y., Lee, D.S., Cho, S.M., Kim, J.C., Park, M.J., Choi, I.G. 2021. Antioxidant properties of 7 domestic essential oils and identification of physiologically active components of essential oils against candida albicans. Journal of the Korean Wood Science and Technology 49(1): 23-43.

Mahmoud, S.S., Croteau, R.B. 2002. Strategies for transgenic manipulation of monoterpene biosynthesis in plants. Trends in Plant Science 7(8): 366-373.

Min, H.J., Kim, C.S., Hyun, H.J., Bae, Y.S. 2017. Essential oil analysis of illicium anistum L. extracts. Journal of the Korean Wood Science and Technology 45(6): 682-688.

Mohammadhosseini, M., Sarker, S.D., Akbarzadeh, A. 2017. Chemical composition of the essential oils and extracts of Achillea species and their biological activities: A review. Journal of Ethnopharmacology 
199: $257-315$.

Pagano, M., Pepperkok, R., Verde, F., Ansorge, W., Draetta, G. 1992. Cyclin A is required at two points in the human cell cycle. EMBO J 11(3): 961-971.

Peter, M., Herskowitz, I. 1994. Joining the complex: cyclin-dependent kinase inhibitory proteins and the cell cycle. Cell 79(2): 181-184.

Prabuseenivasan, S., Jayakumar, M., Ignacimuthu, S. 2006. In vitro antibacterial activity of some plant essential oils. BMC Complementary and Alternative Medicine 6(39): 1-8.

Pujiarti, R., Kasmudjo, 2016. Chemical compositions and insecticidal activity of eucalyptus urophylla essential oil against culex quinquefasciatus mosquito. Journal of the Korean Wood Science and Technology 44(4): 494-504.

Rogero, S.O., Malmonge, S.M., Lugao, A.B., Ikeda, T.I., Miyamaru, L., Cruz, A.S. 2003. Biocompatibility study of polymeric biomaterials. Artif Organs 27(5): 424-427.
Schausberger, P. 2018. Herbivore-associated bacteria as potential mediators and modifiers of induced plant defense against spider mites and thrips. Frontiers in Plant Science 9: 1107.

Schittny, J.C., Djonov, V., Fine, A., Burri, P.H. 1998. Programmed cell death contributes to postnatal lung development. American Journal of Respiratory Cell and Molecular Biology 18(6): 786-793.

Wang, X.W., Zhan, Q., Coursen, J.D., Khan, M.A., Kontny, H.U., Yu, L., Hollander, M.C., O'Connor, P.M., Fornace Jr, A.J., Harris, C.C. 1999. GADD45 induction of a G2/M cell cycle checkpoint. Proceedings of the National Academy of Science of the United States of America 96(7): 3706-3711. Yang, J., Choi, W.S., Kim, J.W., Lee, S.S., Park M.J. 2019. Anti-inflammatory effect of essential oils extracted from wood of four coniferous tree species. Journal of the Korean Wood Science and Technology 47(6): 674-691. 